УДК 621.315 .592

\title{
Структура ближнего порядка и антиструктурные дефекты олова в пленках аморфного и кристаллического $\mathrm{Ge}_{2} \mathrm{Sb}_{2} \mathrm{Te}_{5}$
}

\author{
(C) А.В. Марченко ${ }^{1}$, Е.И. Теруков ${ }^{2,3}$, Ф.С. Насрединов ${ }^{4}$, Ю.А. Петрушин ${ }^{1}$, П.П. Серегин ${ }^{1, \text { ॠ }}$ \\ ${ }^{1}$ Российский государственный педагогический университет им. А.И. Герцена, \\ 191186 Санкт-Петербург, Россия \\ ${ }^{2}$ Физико-технический институт им. А.Ф. Иофффе Российской академии наук, \\ 194021 Санкт-Петербург, Россия \\ ${ }^{3}$ Санкт-Петербургский государственный электротехнический университет „ЛЭТИ“ им. В.И. Ульянова (Ленина), \\ 197376 Санкт-Петербург, Россия \\ ${ }^{4}$ Санкт-Петербургский политехнический университет Петра Великого, \\ 195251 Санкт-Петербург, Россия \\ ฯ E-mail: ppseregin@mail.ru
}

Поступила в Редакцию 21 сентября 2020 г.

В окончательной редакции 23 сентября 2020 г.

Принята к публикации 23 сентября 2020 г.

\begin{abstract}
Методом абсорбционной мессбауэровской спектроскопии на примесных центрах ${ }^{119} \mathrm{Sn}$ показано, что атомы германия в структуре аморфных и поликристаллических пленок $\mathrm{Ge}_{2} \mathrm{Sb}_{2} \mathrm{Te}_{5}$ имеют различную симметрию локального окружения (тетраэдрическую в аморфной фазе и октаэдрическую в кристаллической фазе). Методом эмиссионной мессбауэровской спектроскопии на примесных центрах ${ }^{119 m} \mathrm{Sn}$, образующихся после радиоактивного распада материнских атомов ${ }^{119} \mathrm{Sb}$ и ${ }^{119 m} \mathrm{Te}$, идентифицированы антиструктурные дефекты олова в узлах сурьмы и теллура кристаллических пленок $\mathrm{Ge}_{2} \mathrm{Sb}_{2} \mathrm{Te}_{5}$.
\end{abstract}

Ключевые слова: антиструктурные дефекты, мессбауэровская спектроскопия, $\mathrm{Ge}_{2} \mathrm{Sb}_{2} \mathrm{Te}_{5}$.

DOI: $10.21883 /$ FTP.2021.01.50376.9524

\section{1. Введение}

Устройства фазовой памяти (ФП) на основе халькогенидных полупроводников в настоящее время используют главным образом обратимые переходы из аморфного в кристаллическое состояние тонких пленок состава $\mathrm{Ge}-\mathrm{Sb}-\mathrm{Te}$, а среди них наибольший интерес вызывает состав $\mathrm{Ge}_{2} \mathrm{Sb}_{2} \mathrm{Te}_{5}$. Соединение $\mathrm{Ge}_{2} \mathrm{Sb}_{2} \mathrm{Te}_{5}$ не удается получить в виде объемного стекла, но методом магнетронного распыления мишени возможно получение его аморфных пленок. Совершенствование устройств ФП и технологии их получения должно опираться на исследования процесса кристаллизации аморфных пленок $\mathrm{Ge}_{2} \mathrm{Sb}_{2} \mathrm{Te}_{5}$. В этих исследованиях принципиальным является получение информации о локальной структуре аморфной пленки и сравнение ее со структурой кристалла. Невозможно описать механизм ФП без знания структурных трансформаций при обратимых фазовых переходах между аморфным и кристаллическим состояниями. Например, на ранних этапах исследования пленок $\mathrm{Ge}_{2} \mathrm{Sb}_{2} \mathrm{Te}_{5}$ по результатам, полученным методом XANES (околопороговая тонкая структура рентгеновского спектра поглощения) [1], была предложена модель быстрого обратимого перехода из кристаллического состояния в аморфное для указанных пленок (модель „вывернутого зонтика" ${ }^{6}$.

Переход из аморфного состояния в кубическую кристаллическую фазу и обратно используется в устройствах ФП на $\mathrm{Ge}_{2} \mathrm{Sb}_{2} \mathrm{Te}_{5}$ чаще всего. Однако рабо- чие температуры таких устройств ограничены $120^{\circ} \mathrm{C}$ из-за низкой термической устойчивости аморфной фазы. В недавней работе [2] было предложено заменить переход аморфная-кубическая фаза на переход из метастабильной кубической в стабильную гексагональную фазу в тех же пленках. Такая замена дает комбинацию высокого оптического контраста, термостабильности, малого изменения плотности и увеличивает максимальную рабочую температуру оптики до $240^{\circ} \mathrm{C}$. Авторы [2] связывают высокий оптический контраст с увеличением разницы в структурном беспорядке при переходе от кубической фазы к гексагональной. В связи с этим возникает необходимость исследования структуры и степени разупорядочения обеих кристаллических фаз $\mathrm{Ge}_{2} \mathrm{Sb}_{2} \mathrm{Te}_{5}$.

Эффективным методом исследования структурных перестроений в твердых телах является мессбауэровская спектроскопия [3]. Ключевым требованием к мессбауэровским зондам, используемым для таких целей, является возможность их локализации в определенном узле кристаллической решетки или структурной сетки аморфного материала. При использовании абсорбционной спектроскопии для исследования локальной структуры кристаллических и аморфных пленок $\mathrm{Ge}_{2} \mathrm{Sb}_{2} \mathrm{Te}_{5}$ это требование выполняется на изотопах ${ }^{125} \mathrm{Te},{ }^{121} \mathrm{Sb}$ и ${ }^{119} \mathrm{Sn}$. Зондами для узлов теллура и сурьмы могут служить ${ }^{125} \mathrm{Te}$ и ${ }^{121} \mathrm{Sb}$, а атомы олова ${ }^{119} \mathrm{Sn}$, как было ранее показано [4-6], изовалентно замещают атомы германия в структуре как стеклообразных, так и кристаллических теллуридов германия. Дополнительно может быть ис- 


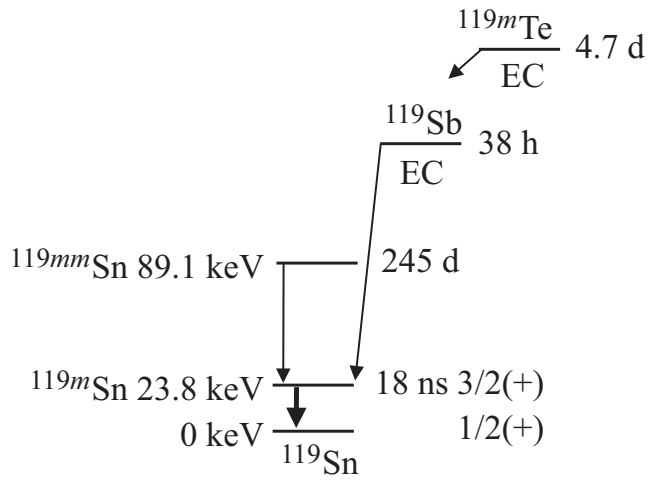

Рис. 1. Схема распада материнских изотопов ${ }^{119 m m} \mathrm{Sn},{ }^{119} \mathrm{Sb}$ и ${ }^{119 m}$ Те.

пользована эмиссионная мессбауэровская спектроскопия на изотопе ${ }^{119 m} \mathrm{Sn}$ с материнскими ядрами ${ }^{119} \mathrm{Sb}$ и ${ }^{119 m} \mathrm{Te}$. Материнские ядра определенно вводятся в узлы сурьмы и теллура соответственно. Образующийся согласно схеме распада ${ }^{119} \mathrm{Sb}$ и ${ }^{119 m}$ Те на рис. 1 дочерний мессбауэровский зонд ${ }^{119 m} \mathrm{Sn}$ может наследовать либо узлы сурьмы (если используется изотоп $\left.{ }^{119} \mathrm{Sb}\right)$, либо узлы теллура (если используется изотоп $\left.{ }^{119 m} \mathrm{Te}\right)$. Особенностью такого процесса является получение моделей антиструктурных дефектов - олово (как аналог германия) в узлах сурьмы или теллура.

В настоящей работе для исследования структурных перестроений в пленках $\mathrm{Ge}_{2} \mathrm{Sb}_{2} \mathrm{Te}_{5}$ используются описанные выше абсорбционные и эмиссионные методики. Целью таких исследований является информация как о структурных перестроениях в локальном окружении атомов германия, сурьмы и теллура в процесс кристаллизации аморфных пленок, так и о природе дефектов олова в структуре кристаллических пленок. Для интерпретации полученных данных были проведены также аналогичные исследования кристаллических соединений $\mathrm{Sb}_{2} \mathrm{Te}_{3}, \mathrm{GeTe}$ и стеклообразного сплава $\mathrm{Ge}_{1.5} \mathrm{Te}_{8.5}$.

\section{2. Методика эксперимента}

Исследованные в работе соединения $\mathrm{Ge}_{2} \mathrm{Sb}_{2} \mathrm{Te}_{5}$, $\mathrm{Ge}_{1.95} \mathrm{Sn}_{0.05} \mathrm{Sb}_{2} \mathrm{Te}_{5}, \quad \mathrm{Sb}_{2} \mathrm{Te}_{3}, \quad \mathrm{GeTe}$ и сплавы $\mathrm{Ge}_{1.45} \mathrm{Sn}_{0.05} \mathrm{Te}_{8.5}, \quad \mathrm{Ge}_{1.5} \mathrm{Te}_{8.5}, \quad \mathrm{Ge}_{1.5} \mathrm{As}_{0.4} \mathrm{Te}_{8.1}$, $\mathrm{Ge}_{1.45} \mathrm{Sn}_{0.05} \mathrm{As}_{0.4} \mathrm{Te}_{8.1}$ были синтезированы из элементарных веществ при $1050^{\circ} \mathrm{C}$ в откачанных до $10^{-3}$ мм рт. ст. кварцевых ампулах.

Рентгеноаморфные пленки $\mathrm{Ge}_{2} \mathrm{Sb}_{2} \mathrm{Te}_{5}$, $\mathrm{Ge}_{1.95} \mathrm{Sn}_{0.05} \mathrm{Sb}_{2} \mathrm{Te}_{5}, \quad \mathrm{GeTe}, \mathrm{Ge}_{1.45} \mathrm{Sn}_{0.05} \mathrm{Te}_{8.5}, \mathrm{Ge}_{1.5} \mathrm{Te}_{8.5}$ были получены методом магнетронного распыления на постоянном токе в атмосфере азота мишеней аналогичного состава. Для получения пленок $\mathrm{Ge}_{1.95} \mathrm{Sn}_{0.05} \mathrm{Sb}_{2} \mathrm{Te}_{5}$ и $\mathrm{Ge}_{1.45} \mathrm{Sn}_{0.05} \mathrm{Te}_{8.5}$ использовался препарат ${ }^{119} \mathrm{Sn}$ с обогащением 92\%. Кристаллизация аморфных пленок $\mathrm{Ge}_{2} \mathrm{Sb}_{2} \mathrm{Te}_{5}$ и $\mathrm{Ge}_{1.95} \mathrm{Sn}_{0.05} \mathrm{Sb}_{2} \mathrm{Te}_{5}$ проводилась при температурах $150^{\circ} \mathrm{C}$ (с образованием кубической фазы $f c c$ ) или $310^{\circ} \mathrm{C}$ (с образованием гексагональной фазы $h c p)$ [7-10]. Кристаллизация аморфных пленок $\mathrm{Ge}_{1.5} \mathrm{Te}_{8.5}$ и $\mathrm{Ge}_{1.45} \mathrm{Sn}_{0.05} \mathrm{Te}_{8.5}$ проводилась при $250^{\circ} \mathrm{C}$.

Мессбауэровские источники ${ }^{119 m} \mathrm{Sn}$ на основе кристаллических пленок $\mathrm{Ge}_{2} \mathrm{Sb}_{2} \mathrm{Te}_{5}$ (hcp-фаза) были приготовлены путем диффузии безносительных изотопов ${ }^{119} \mathrm{Sb}$ или ${ }^{119 m}$ Те в тонкие аморфные пленки при температуpe $310^{\circ} \mathrm{C}$ в течение 10 ч. Мессбауэровские источники ${ }^{119 m} \mathrm{Sn}$ на основе $\mathrm{Sb}_{2} \mathrm{Te}_{3}$ и GeTe готовили сплавлением соответствующего соединения с безносительными изотопами ${ }^{119} \mathrm{Sb}$ или ${ }^{119 m}$ Те в запаянных ампулах.

Изотопы ${ }^{119} \mathrm{Sb}$ и ${ }^{119 m} \mathrm{Te}$ были получены соответственно по реакциям ${ }^{119} \mathrm{Sn}(p, n){ }^{119} \mathrm{Sb}$ и ${ }^{117} \mathrm{Sn}(\alpha, 2 n){ }^{119 m} \mathrm{Te}$ с последующим хроматографическим выделением безносительных препаратов ${ }^{119} \mathrm{Sb}$ и ${ }^{119 m} \mathrm{Te}$.

Все мессбауэровские спектры измерялись на спектрометре CM 4201 TerLab при $80 \mathrm{~K}$.

При измерении эмиссионных спектров использовался поглотитель $\mathrm{CaSnO}_{3}$ (поверхностная плотность по олову $\left.5 \mathrm{Mг} / \mathrm{cm}^{2}\right)$. Спектр этого поглотителя с источником того же состава представлял собой одиночную линию с шириной на полувысоте $G=0.79(1) \mathrm{Mм} / \mathrm{c}$, которая принималась за аппаратурную ширину спектральной линии. Для источников, приготовленных с использованием ${ }^{119 m}$ Те, спектры снимались после установления динамического радиоактивного равновесия между изотопами ${ }^{119} \mathrm{Sb}$ и ${ }^{119 m}$ Те. Изомерные сдвиги мессбауэровских спектров ${ }^{119 m} \mathrm{Sn}$ и ${ }^{119} \mathrm{Sn}$ приводятся относительно поглотителя $\mathrm{CaSnO}_{3}$.

При измерении абсорбционных спектров ${ }^{119} \mathrm{Sn},{ }^{121} \mathrm{Sb}$ и ${ }^{125} \mathrm{Te}$ использовались источники $\mathrm{Ca}^{119 m m} \mathrm{SnO}_{3}, \mathrm{Ca}^{121} \mathrm{SnO}_{3}$ и $\mathrm{Zn}^{125 m} \mathrm{Te}$ соответственно. Аппаратурные ширины спектральных линий $\left(G_{\text {app }}\right)$ для спектров ${ }^{119} \mathrm{Sn},{ }^{121} \mathrm{Sb},{ }^{125} \mathrm{Te}$ составляли соответственно 0.79(2), 2.35(6), 6.20(6) мM/с. Изомерные сдвиги (IS) спектров ${ }^{119} \mathrm{Sn},{ }^{121} \mathrm{Sb}$ и ${ }^{125} \mathrm{Te}$ приводятся относительно поглотителей $\mathrm{CaSnO}_{3}, \mathrm{InSb}$ и ZnTe соответственно.

Состав аморфных и кристаллических пленок, а также состав мишени контролировались методом рентенофлуоресцентного анализа (РФА). Для этого из элементарных веществ были синтезированы поликристаллические сплавы $\mathrm{Ge}_{x} \mathrm{Sb}_{y} \mathrm{Te}_{1-x-y}$ $\left(\mathrm{Ge}_{0.22} \mathrm{Sb}_{0.22} \mathrm{Te}_{0.56}, \quad \mathrm{Ge}_{0.14} \mathrm{Sb}_{0.29} \mathrm{Te}_{0.57}, \mathrm{Ge}_{0.8} \mathrm{Sb}_{0.34} \mathrm{Te}_{0.58}\right.$, $\mathrm{Sb}_{0.40} \mathrm{Te}_{0.60}$ и $\left.\mathrm{Ge}_{0.50} \mathrm{Te}_{0.50}\right)$. Значения $x$ и $y$ указаны по составу исходной шихты с погрешностью \pm 0.005 . Рентгенофлуоресцентные спектры измерялись на спектрометре X-Art M при значении анодного напряжения 35 кВ с палладиевым антикатодом. Определялись площади под флуоресцентными $K_{\alpha}$-линиями германия, $S_{\mathrm{Ge}}$, сурьмы, $S_{\mathrm{Sb}}$ и теллура, $S_{\mathrm{Te}}$, а далее с помощью соотношений типа $x_{\mathrm{RFA}}=S_{\mathrm{Ge}} /\left(S_{\mathrm{Ge}}+S_{\mathrm{Sb}}+S_{\mathrm{Te}}\right)$ вычислялись относительные площади спектральных линий германия, сурьмы и теллура. Индекс „RFA“ указывает на получение значений $x$ и $y$ из данных рентгенофлуоресцентного анализа. Экспериментальные значения среднеквадратичных отклонений $x_{\text {RFA }}$ и $y_{\text {RFA }}$ при многократных измерениях не превышали \pm 0.02 . На рис. 2 представлены зависимости $x=f\left(x_{\mathrm{RFA}}\right)$ и 

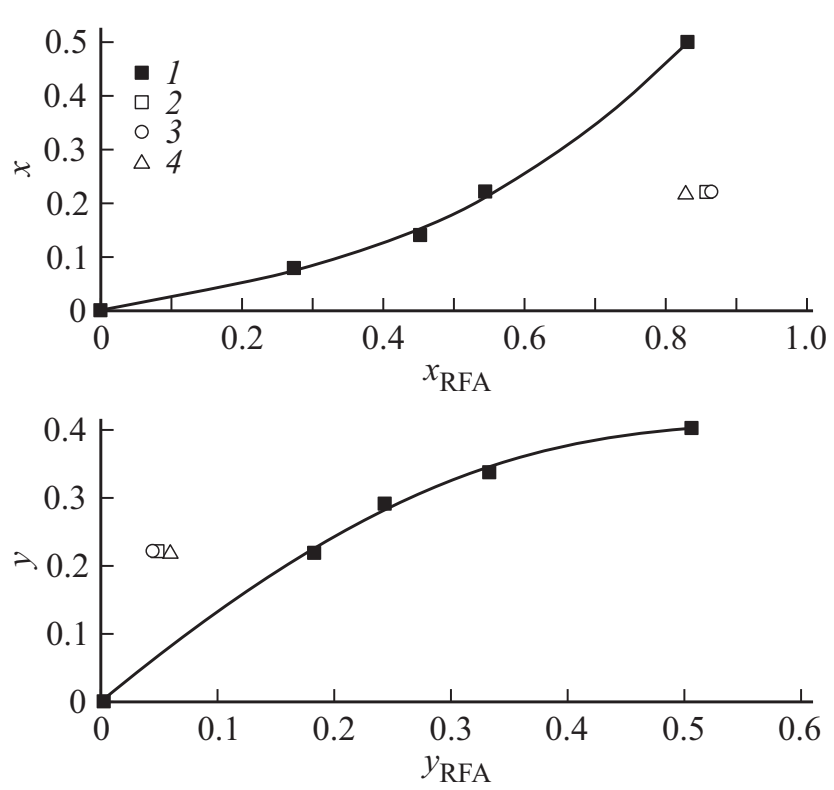

Рис. 2. Зависимости $x=f\left(x_{\mathrm{RFA}}\right)$ и $y=f\left(y_{\mathrm{RFA}}\right)$ для поликристаллических сплавов (1) и пленок толщиной 40 нм (спектры измерялись для аморфной (2) и поликристаллической (3) пленок), 60 нм (спектры измерялись для аморфной пленки (4)).

$y=f\left(y_{\mathrm{RFA}}\right)$ для поликристаллических сплавов и пленок (аморфных и кристаллических) различной толщины. Эти зависимости для поликристаллических сплавов удовлетворительно аппроксимируются полиномами $x=0.6187 x_{\mathrm{RFA}}^{3}-0.0922 x_{\mathrm{RFA}}^{2}+0.2531 x_{\mathrm{RFA}}(R=0.998)$ и $y=-0.3227 y_{\mathrm{RFA}}^{3}-1.1385 y_{\mathrm{RFA}}^{2}+1.4487 y_{\mathrm{RFA}} \quad(R=0.999)$, где $R$ - коэффициент достоверности аппроксимации.

Для пленок экспериментальные данные рентгенофлюоресцентного анализа (РФА) существенно отклоняются от зависимостей $x=f\left(x_{\mathrm{RFA}}\right)$ и $y=f\left(y_{\mathrm{RFA}}\right)$, полученных для поликристаллических сплавов. Кроме того, данные РФА для пленок зависят от их толщины (см., например, экспериментальные точки 3 и 4 на рис. 2). Поэтому для контроля состава пленок были приготовлены пленки-

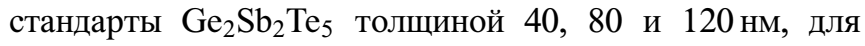
которых методом оже-спектроскопии определялся состав. Далее, в процессе напыления исследуемых пленок выдерживалась их толщина и проводилось сравнение параметров $x, y$ и $z$ с соответствующими параметрами спектров стандартов.

\section{3. Экспериментальные результаты и их обсуждение}

\section{1. Данные абсорбционной мессбауэровской спектроскопии ${ }^{119} \mathrm{Sn}$}

Типичные спектры примесных атомов ${ }^{119} \mathrm{Sn}$ в аморфных (стеклообразных) и поликристаллических материалах, приведенные на рис. 3 и 4, представляют собой одиночные уширенные линии $(G \approx 1.15-1.35 \mathrm{MM} / \mathrm{c})$. Спектры ${ }^{119} \mathrm{Sn}$ в аморфном $\mathrm{Ge}_{2} \mathrm{Sb}_{2} \mathrm{Te}_{5}$ и стеклообразном
$\mathrm{Ge}_{1.5} \mathrm{Te}_{8.5}$ имеют изомерные сдвиги $I S \approx 2.06-2.09 \mathrm{MM} / \mathrm{c}$. Такие изомерные сдвиги типичны для спектров ${ }^{119} \mathrm{Sn}$ соединений четырехвалентного олова с тетраэдрической системой химических связей $\mathrm{Sn}-\mathrm{IV}[3,4]$. Спектры ${ }^{119} \mathrm{Sn}$ поликристаллических образцов $\mathrm{Ge}_{2} \mathrm{SnSb}_{2} \mathrm{Te}_{5}$ в обеих фазах, $f c c$ и $h c p$, а также $\mathrm{Ge}_{1.5} \mathrm{Te}_{8.5}$ имеют изомерные сдвиги $I S \approx 3.49-3.52 \mathrm{mм} / \mathrm{c}$, близкие к изомерному сдвигу спектра ${ }^{119} \mathrm{Sn}$ соединения двухвалентного олова с теллуром, $I S=3.55(2) \mathrm{Mм} / \mathrm{c}$, в котором реализуется октаэдрическая система химических связей.

Исходя из величин изомерных сдвигов спектров ${ }^{119} \mathrm{Sn}$ можно сделать вывод, что атомы олова и замещаемые ими атомы германия в структурной сетке аморфного $\mathrm{Ge}_{2} \mathrm{Sb}_{2} \mathrm{Te}_{5}$ и стеклообразного $\mathrm{Ge}_{1.5} \mathrm{Te}_{8.5}$ образуют тетраэдрическую $s p^{3}$-систему химических связей. Поскольку в структурной сетке стеклообразного сплава $\mathrm{Ge}_{1.5} \mathrm{Te}_{8.5}$ атомы германия (олова) могут иметь в сво-

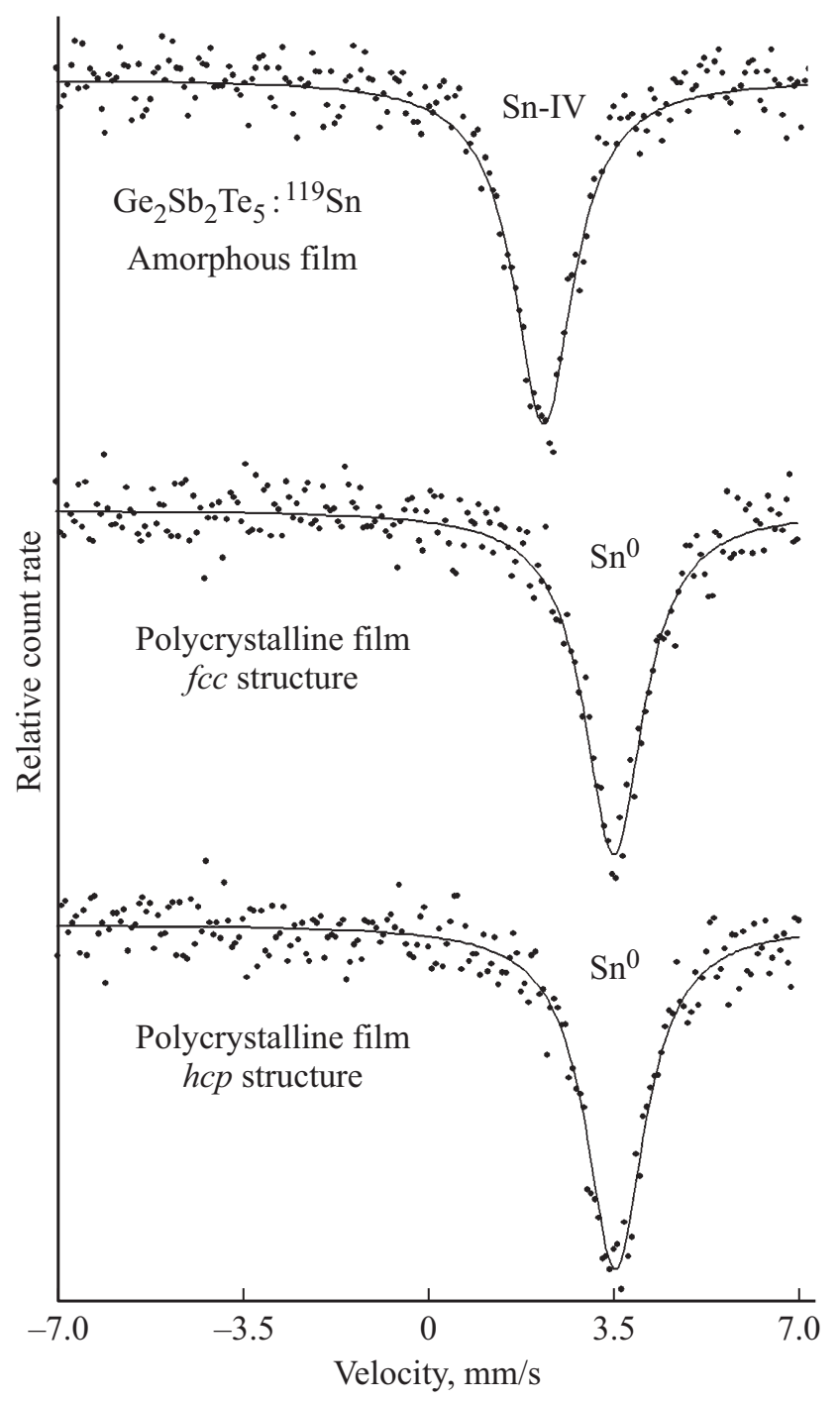

Рис. 3. Абсорбционные мессбауэровские спектры примесных атомов ${ }^{119} \mathrm{Sn}$ в аморфных и поликристаллических пленках $\mathrm{Ge}_{2} \mathrm{Sb}_{2} \mathrm{Te}_{5}$. Показано положение спектральных линий, отвечающих центрам $\mathrm{Sn}-\mathrm{IV}$ и $\mathrm{Sn}^{2+}$. 


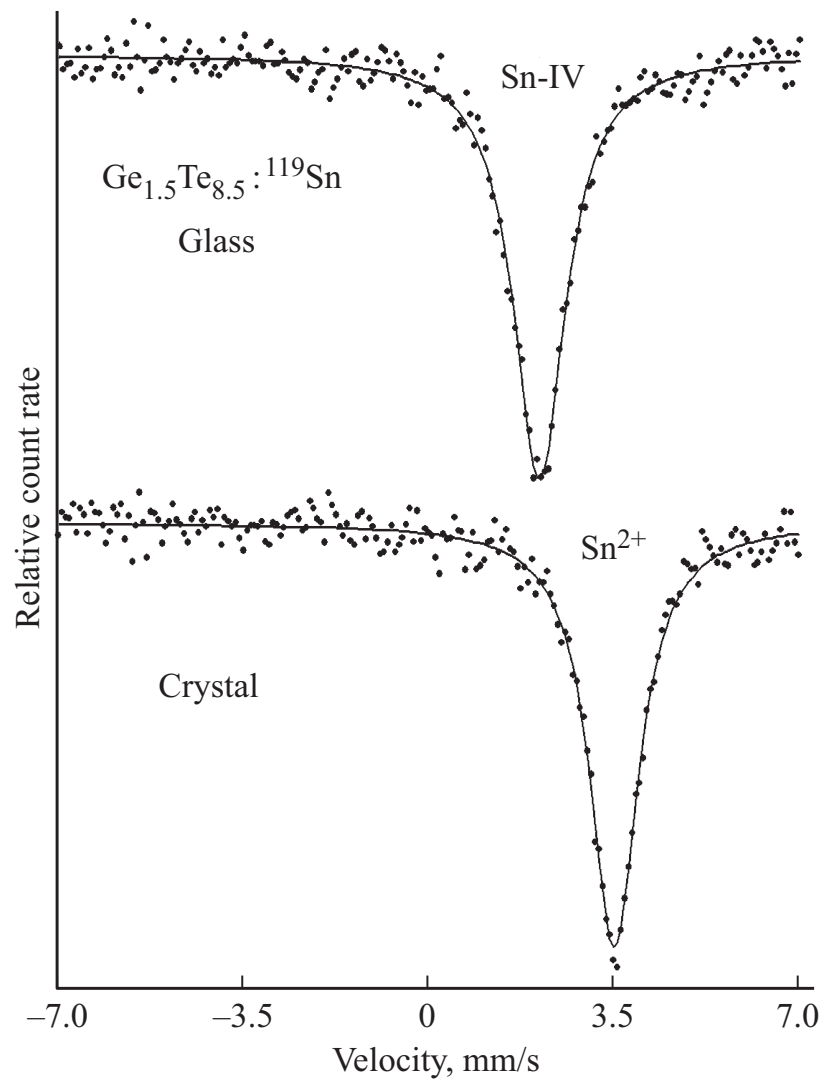

Pис. 4. Абсорбционные мессбауэровские спектры примесных атомов ${ }^{119} \mathrm{Sn}$ в стеклообразном и поликристаллическом сплаве $\mathrm{Ge}_{1.5} \mathrm{Te}_{8.5}$. Показано положение спектральных линий, отвечающих центрам $\mathrm{Sn}-\mathrm{IV}$ и $\mathrm{Sn}^{2+}$.

ем локальном окружении только атомы теллура, близость изомерных сдвигов всех исследованных аморфных материалов свидетельствует о том, что и в структурной сетке аморфного $\mathrm{Ge}_{2} \mathrm{Sb}_{2} \mathrm{Te}_{5}$ атомы германия (олова) связаны только с атомами теллура. Уширение спектров ${ }^{119} \mathrm{Sn}$ всех исследованных аморфных материалов объясняется отсутствием в них дальнего порядка в расположении атомов и является характерным свойством мессбауэровских спектров неупорядоченных структур.

Близость изомерных сдвигов спектров ${ }^{119} \mathrm{Sn}$ в поликристаллических $\mathrm{Ge}_{2} \mathrm{Sb}_{2} \mathrm{Te}_{5}$ и $\mathrm{Ge}_{1.5} \mathrm{Te}_{8.5}$ к изомерному сдвигу соединения SnTe указывает на то, что при кристаллизации в локальном окружении атомов германия (олова) остаются только атомы теллура. Ширина спектров поликристаллических образцов существенно больше аппаратурной ширины. Это свидетельствует о том, что в их составе олово не образует соединение SnTe (кристаллическая решетка типа $\mathrm{NaCl}$ ), а входит в состав твердых растворов $\mathrm{Ge}_{1-x} \mathrm{Sn}_{x} \mathrm{Te}$ (в сплаве $\mathrm{Ge}_{1.5} \mathrm{Te}_{8.5}$ ) или в состав фаз $f c c$ и $h c p$ (в пленках $\mathrm{Ge}_{2} \mathrm{Sb}_{2} \mathrm{Te}_{5}$ ). Согласно данным рентгеноструктурного анализа, твердые растворы $\mathrm{Ge}_{1-x} \mathrm{Sn}_{x} \mathrm{Te}$ и $f c c$-фаза $\mathrm{Ge}_{2} \mathrm{Sb}_{2} \mathrm{Te}_{5}$ имеют ромбоэдрически искаженные решетки типа $\mathrm{NaCl}$, а $h c$-фаза $\mathrm{Ge}_{2} \mathrm{Sb}_{2} \mathrm{Te}_{5}$ имеет решетку с 9-слойной тригональной упаковкой атомов $-\mathrm{Te}-\mathrm{Sb}-\mathrm{Te}-\mathrm{Ge}-\mathrm{Te}-\mathrm{Te}-\mathrm{Ge}-\mathrm{Te}-\mathrm{Sb}-[7-10]$. Некубическое искажение решеток должно приводить к квадрупольному расщеплению мессбауэровских спектров ${ }^{119} \mathrm{Sn}$ на величину, меньшую в данном случае ширины спектральной линии.

\section{2. Данные эмиссионной мессбауэровской спектроскопии ${ }^{119 m} \mathrm{Sn}$}

В процессе диффузионного легирования аморфных пленок $\mathrm{Ge}_{2} \mathrm{Sb}_{2} \mathrm{Te}_{5}$ примесными атомами ${ }^{119} \mathrm{Sb}$ и ${ }^{119 m} \mathrm{Te}$ при температуре $\sim 310^{\circ} \mathrm{C}$ происходит кристаллизация пленок с образованиеми hcp-фазы [7-10]. Типичные спектры примесных атомов ${ }^{119 m} \mathrm{Sn}$, образовавшихся после радиоактивного распада атомов ${ }^{119} \mathrm{Sb}$ в узлах сурьмы и атомов ${ }^{119 m}$ Те в узлах теллура кристаллической пленки, приведены на рис. 5.

В случае материнских атомов ${ }^{119} \mathrm{Sb}$ спектр представляет собой одиночную уширенную линию $(G=1.32(2) \mathrm{Mм} / \mathrm{c})$. Изомерный сдвиг этого спектра, $I S=3.47(2) \mathrm{Mм} / \mathrm{c}$, отвечает двухвалентному олову $\mathrm{Sn}^{2+}$. Близкие параметры имеет спектр примесных атомов

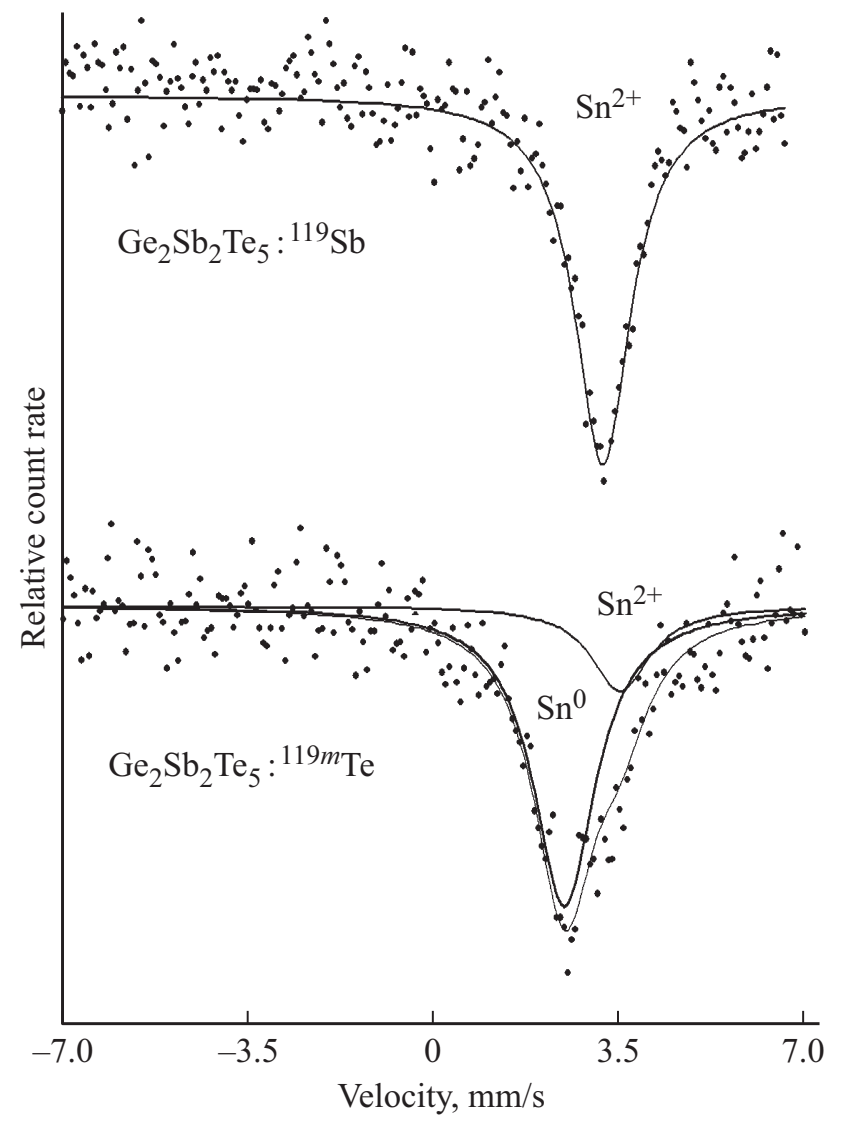

Рис. 5. Эмиссионные мессбауэровские спектры примесных атомов ${ }^{119 m} \mathrm{Sn}$, образовавшихся после радиоактивного распада атомов ${ }^{119} \mathrm{Sb}$ в узлах сурьмы, и атомов ${ }^{119 m}$ Те в узлах теллура кристаллической (hc p-фаза) пленки $\mathrm{Ge}_{2} \mathrm{Sb}_{2} \mathrm{Te}_{5}$. Показано положение спектральных линий, отвечающих центрам $\mathrm{Sn}^{2+}$ и $\mathrm{Sn}^{0}$. 


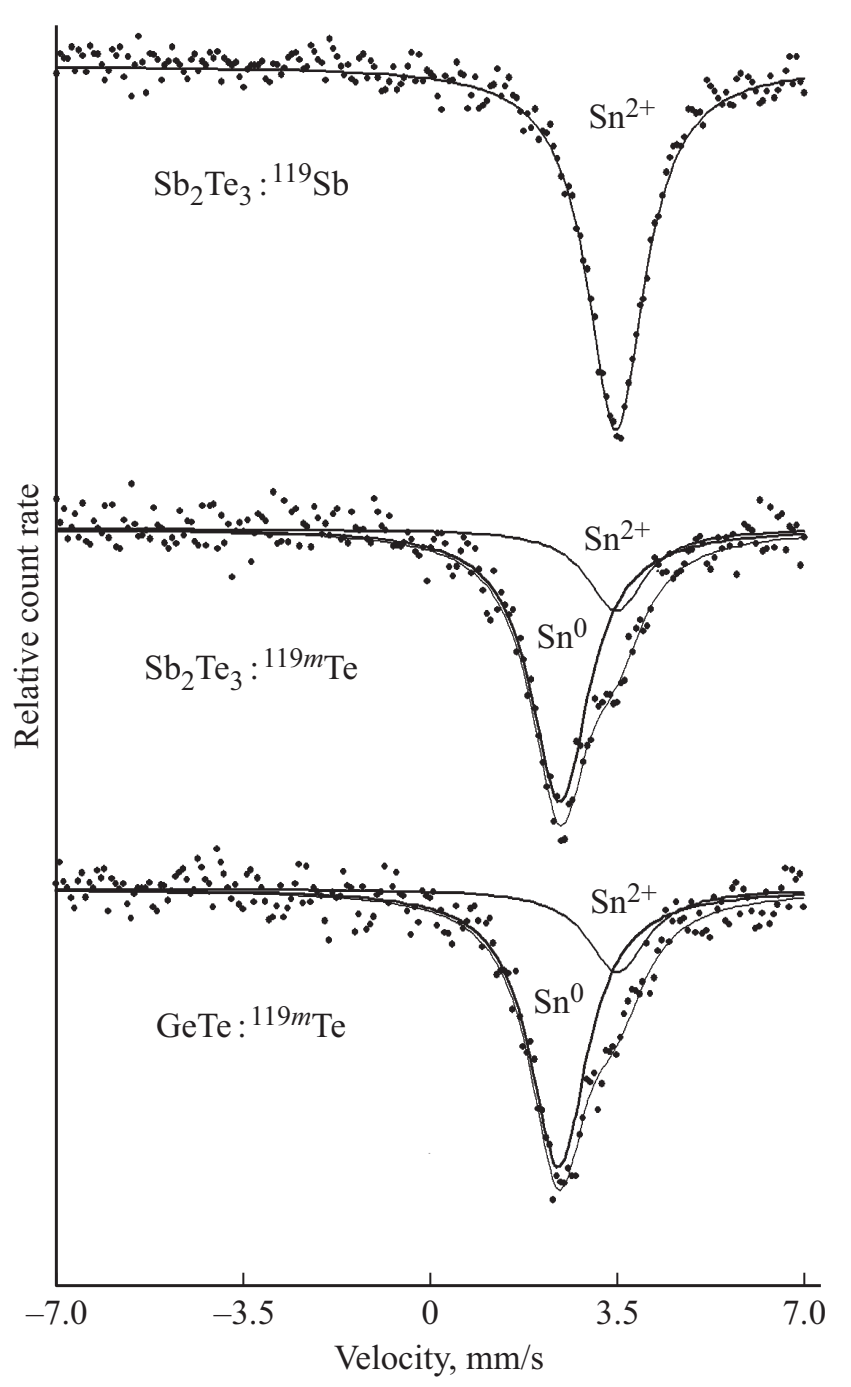

Рис. 6. Эмиссионные мессбауэровские спектры примесных атомов ${ }^{119 m} \mathrm{Sn}$, образовавшихся после радиоактивного распада атомов ${ }^{119} \mathrm{Sb}$ в узлах сурьмы, и атомов ${ }^{119 m}$ Те в узлах теллура соединений $\mathrm{Sb}_{2} \mathrm{Te}_{3}$ и $\mathrm{GeTe}$. Показано положение спектральных линий, отвечающих центрам $\mathrm{Sn}^{2+}$ и $\mathrm{Sn}^{0}$.

${ }^{119 m} \mathrm{Sn}$, образующихся после радиоактивного распада материнских атомов ${ }^{119} \mathrm{Sb}$ в узлах сурьмы кристаллической решетки $\mathrm{Sb}_{2} \mathrm{Te}_{3}$ (см. рис. 6, см. также [11]). Исходя из этого можно сделать вывод, что в обоих случаях в локальном окружении атомов ${ }^{119 m} \mathrm{Sn}^{2+}$ находятся атомы теллура. Это согласуется с данными $h c p$-структуры кристаллических пленок $\mathrm{Ge}_{2} \mathrm{Sb}_{2} \mathrm{Te}_{5}$ [7], согласно которым в локальном окружении атомов сурьмы находятся атомы теллура. Аналогичные параметры имеет спектр примесных атомов ${ }^{119 m} \mathrm{Sn}$, образующихся после радиоактивного распада материнских атомов ${ }^{119} \mathrm{Sb}$ в узлах сурьмы кристаллической решетки $\mathrm{Sb}_{2} \mathrm{Te}_{3}$ (см. рис. 6, см. также [11]), и можно сделать вывод, что в обоих случаях в локальном окружении атомов ${ }^{119 m} \mathrm{Sn}^{2+}$ находятся только атомы теллура.

В случае материнских атомов ${ }^{119 m}$ Те спектр представляет собой наложение двух уширенных линий
$(G=1.41-1.46 \mathrm{Mm} / \mathrm{c})$. Более интенсивная линия с изомерным сдвигом $I S=2.42(2) \mathrm{Mм} / \mathrm{c}$, лежащим в области изомерных сдвигов спектров интерметаллических соединений олова, отвечает центрам ${ }^{119 m} \mathrm{Sn}^{0}$, образовавшимся после распада материнских атомов ${ }^{119 m}$ Те в узлах теллура. В слоистой решетке $h c p$-фазы $\mathrm{Ge}_{2} \mathrm{Sb}_{2} \mathrm{Te}_{5}$ имеются три типа слоев теллура [5], что приводит к появлению неоднородного изомерного сдвига в дополнение к квадрупольному расщеплению и значительному уширению спектральной линии.

Менее интенсивная линия с $I S=3.51(2) \mathrm{Mм} / \mathrm{c}$ отвечает центрам ${ }^{119 m} \mathrm{Sn}^{2+}$, образовавшимся после распада материнских атомов ${ }^{119 m} \mathrm{Te}$, сместившихся из узлов теллура в узлы $\mathrm{Sb}$ или $\mathrm{Ge}$, за счет энергии отдачи, сопровождающей радиоактивный распад изотопа ${ }^{119 m} \mathrm{Te}$. Набор узлов, в которые смещается дочерний атом ${ }^{119} \mathrm{Sb}$, также приводит к неоднородному изомерному сдвигу и к значительному уширению спектральной линии.

Аналогичную структуру имеют спектры примесных атомов ${ }^{119 m} \mathrm{Sn}$, образующиеся после радиоактивного распада материнских атомов ${ }^{119 m} \mathrm{Te}$ в узлах теллура кристаллических решеток $\mathrm{Sb}_{2} \mathrm{Te}_{3}$ и GeTe (см. рис. 6), и можно сделать вывод, что во всех случаях в локальном окружении атомов ${ }^{119 m} \mathrm{Sn}^{2+}$ находятся только атомы теллура.

Атомы ${ }^{119 m} \mathrm{Sn}$, которые в результате электронного захвата из ${ }^{119} \mathrm{Sb}$ или цепочки электронных захватов из ${ }^{119 m}$ Те оказываются зафиксированными в узлах $\mathrm{Sb}$ или Те решетки $h c p \mathrm{Ge}_{2} \mathrm{Sb}_{2} \mathrm{Te}_{5}$, можно рассматривать как модели антиструктурных дефектов, так как электронный аналог атома одной подрешетки (германиевой) оказывается в узле другой подрешетки.

\section{4. Заключение}

Показано, что атомы олова и замещаемые ими атомы германия в структуре аморфных и поликристаллических $\mathrm{Ge}_{2} \mathrm{Sb}_{2} \mathrm{Te}_{5}$ и $\mathrm{Ge}_{1.5} \mathrm{Te}_{8.5}$ имеют различную симметрию локального окружения (тетраэдрическую в аморфной фазе и октаэдрическую в кристаллической фазе). Этот вывод находится в согласии с результатами исследований пленок $\mathrm{Ge}_{2} \mathrm{Sb}_{2} \mathrm{Te}_{5}$ методом XANES [1]. Методом эмиссионной мессбауэровской спектроскопии на примесных центрах ${ }^{119 m} \mathrm{Sn}$, образующихся после радиоактивного распада материнских атомов ${ }^{119} \mathrm{Sb}$ и ${ }^{119 m} \mathrm{Te}$, идентифицированы антиструктурные дефекты олова в узлах сурьмы и теллура кристаллических пленок $\mathrm{Ge}_{2} \mathrm{Sb}_{2} \mathrm{Te}_{5}$. Уширение спектров антиструктурных дефектов объясняется либо набором возможных атомов (сурьмы, германия, теллура) в локальном окружении узлов теллура, либо аналогичным набором узлов, в которые смещается дочерний атом ${ }^{119} \mathrm{Sb}$.

\section{Конфликт интересов}

Авторы заявляют, что у них нет конфликта интересов. 


\section{Список литературы}

[1] A.V. Kolobov, P. Fons, A.I. Frenkel, A.L. Ankudinov, J. Tominaga, T. Uruga. Nature Materials, 3, 703 (2004).

[2] C. Hu, Z. Yang, C. Bi, H. Peng, L. Ma, C. Zhang, Z. Gu, J. Zhu. Acta Materialia, 188, 121 (2020).

[3] K. Bobokhuzhaev, A. Marchenko, P. Seregin. Structural and antistructural defects in chalcogenide semiconductors. Mössbauer spectroscopy (Academic Pubblishing, 2020).

[4] Л.Н. Серегина, Ф.С. Насрединов, Б.Т. Мелех, 3.В. Маслова, Э.Ю. Тураев, П.П. Серегин. Физика и химия стекла, 3, 328 (1977).

[5] M. Micoulaut, K. Gunasekera, S. Ravindren, P. Boolchand. Phys. Rev. B, 90, 094207 (2014).

[6] А.В. Марченко, П.П. Серегин, Е.И. Теруков, К.Б. Шахович. ФТП, 53, 718 (2019).

[7] T. Kato, K. Tanaka. Jpn. J. Appl. Phys., 44, 7340 (2005).

[8] R.M. Shelby, S. Raoux. J. Appl. Phys., 105, 104902 (2009).

[9] T. Siegrist, P. Jost, H. Volker. Nature Materials, 10, 202 (2011).

[10] V. Sousa. Microelectronic Engin., 88, 807 (2011).

[11] F. Ambe, S. Ambe. J. Chem. Phys., 73, 2029 (1980).

Редактор Л.В. Шаронова

\section{LOCAL STRUCTURE OF GERMANIUM ATOMS AND ANTI-STRUCTUR DEFECTS OF TIN IN AMORPHOUS AND CRYSTALLINE $\mathrm{Ge}_{2} \mathrm{Sb}_{2} \mathrm{Te}_{5}$ FILMS}

A.V. Marchenko ${ }^{1}$, E.I. Terukov ${ }^{2,3}$, F.S. Nasredinov ${ }^{4}$, Yu.A. Petrushin ${ }^{1}$, P.P. Seregin ${ }^{1}$

${ }^{1}$ Herzen State Pedagogical University of Russia, 191186 St. Petersburg, Russia

${ }^{2}$ loffe Institute, 194021 St. Petersburg, Russia

${ }^{3}$ St. Petersburg Electrotechnical University "LETI“, 197376 St. Petersburg, Russia

${ }^{4}$ Peter the Great St.Petersburg Polytechnic University, 195251 St. Petersburg, Russia

\footnotetext{
Abstract The absorption Mössbauer spectroscopy on ${ }^{119} \mathrm{Sn}$ impurity centers has shown that germanium atoms in the structure of amorphous and polycrystalline $\mathrm{Ge}_{2} \mathrm{Sb}_{2} \mathrm{Te}_{5}$ films have different local symmetries (tetrahedral in the amorphous phase and octahedral in the crystalline phase). The emission Mössbauer spectroscopy at ${ }^{119 m} \mathrm{Sn}$ impurity centers formed after radioactive decay of the ${ }^{119} \mathrm{Sb}$ or ${ }^{119 m} \mathrm{Te}$ parent atoms has allowed to identify tin anti-site defects at antimony and tellurium sites of crystalline $\mathrm{Ge}_{2} \mathrm{Sb}_{2} \mathrm{Te}_{5}$ films.
} 